\title{
EDUCAÇÃO EM TEMPO DE PANDEMIA: “TRAVAR O ACELERADOR DE DESIGUALDADES": REFLEXÕES A PARTIR DE PORTUGAL
} Isabel Margarida Duarte*

(iD) https://orcid.org/0000-0001-7908-5649

Como citar este artigo: DUARTE, I. M. Educação em tempo de pandemia: "travar o acelerador de desigualdades": reflexões a partir de Portugal. Todas as Letras - Revista de Língua e Literatura, São Paulo, v. 23, n. 2, p. 1-12, maio/ago. 2021. DOI 10.5935/1980-6914/eLETDO2114609

Submissão: junho de 2021. Aceite: junho de 2021.

Resumo: Tendo como ponto de partida a reflexão sobre a experiência da autora como docente na Faculdade de Letras da Universidade do Porto, durante os dois confinamentos provocados pela Covid-19, o texto relata, criticamente, o essencial do que foi feito em Portugal, no que concerne ao ensino remoto de emergência, e equaciona as perdas em conhecimentos e competências, mas também os constrangimentos que se tornaram oportunidades nesta área. São apontados, no fim, caminhos para o futuro.

Palavras-chave: Covid-19. Portugal. Ensino remoto. Desigualdades. Oportunidades.

\section{INTRODUÇÃo}

$\boldsymbol{R}$ efletir sobre o modo como os sistemas educativos de todo o mundo se adaptaram, com mais ou menos sucesso, à emergência sanitária provocada pelo vírus Sars-CoV-2 tem sido um tema de investigação com 
presença constante nos últimos tempos. Para acudir aos aprendentes, privados de aulas presenciais, milhões de docentes tiveram de se adaptar a soluções alternativas, onde elas existiram, fizeram novas experiências, partilharam, com os seus pares, ideias, materiais e estratégias, frequentaram formações on-line, refletiram sobre como ensinar o melhor possivel nas circunstâncias anómalas sob as quais vivemos. Começa agora a surgir um conjunto vasto de publicações e estudos sobre o que se perdeu em termos de aprendizagens e competências. Os sistemas educativos deitam contas à vida e procuram preparar-se para, num futuro próximo, recuperar as aprendizagens perdidas. Vale também a pena, no entanto, sabermos o que se ganhou, porque essa experiência-limite e a reflexão por ela suscitada também nos deram algumas lições e podem ter sido um ponto de viragem para apontar caminhos urgentes e gerar avanços.

Quando, em março de 2020, subitamente a pandemia da Covid-19 se abateu sobre Portugal, umas semanas depois de uma onda de morte e incredulidade ter começado a assolar a Itália, o país confinou-se totalmente, tendo todas as escolas, de todos os graus de ensino, encerrado as atividades presenciais. De um dia para o outro, literalmente, vimo-nos na necessidade de usar plataformas on-line com as quais a maior parte de nós, quer os docentes quer os estudantes, não estávamos familiarizados. Como Azevedo (2020, p. 83) escreve, "Neste contexto de emergência escolar, escolas, educadores, alunos e famílias tiveram de se adaptar muito rapidamente, o que em geral terá sido alcançado com sucesso (e muito trabalho e muitos danos)". Essa capacidade de adaptação foi igualmente reportada ${ }^{1}$ no estudo de Fraga et al. (2021), que detetou também o aumento das desigualdades existentes entre os alunos, do ponto de vista das aprendizagens realizadas. Deixando de lado o "muito trabalho" exigido pela situação, referido por Joaquim Azevedo, debruçar-nos-emos quer sobre o "sucesso" quer sobre os "muitos danos".

Este texto procurará, depois desta curta introdução, em primeiro lugar, fazer um breve relato dos factos mais relevantes para o ensino, no contexto pandémico da Covid-19; em segundo lugar, refletir, em dois tempos, sobre o que se ganhou e o que se perdeu com esta modalidade do ensino a distância (EaD); por último, pensar em estratégias e medidas de fundo para remediar as aprendizagens que não tiveram lugar. Este percurso pelos meses da pandemia e pelas alterações que trouxeram ao ensino será feito, também, a partir da minha perspetiva pessoal de docente da Faculdade de Letras da Universidade do Porto (Flup).

Parece-nos hoje que são nítidas "as diferenças entre uma educação a distância bem planeada e o ensino remoto de emergência", sendo que "esta tipologia de ensino é uma abordagem rápida, onde não cabem abordagens de design de aprendizagens online com qualidade" (HODGES et al., 2020 apud SILVA, 2021, p. 56). Assim, a reflexão presente neste texto será sempre sobre o ensino remoto de emergência, e não sobre educação a distância bem planeada. Está fora de causa refletirmos sobre o EaD tal como acontece nas grandes universidades deste tipo, como, no caso português, a Universidade Aberta. Iremos pensar, exclusivamente, no que foi feito, remotamente, para chegar a alunos de vários graus de ensino, confinados nas suas casas, de modo a remediar a situação de emergência 
vivida e para que a interrupção das aulas presenciais lhes causasse o mínimo de danos possível, a nivel quer das aprendizagens, quer das competências e, também, a nivel da saúde mental e das vivências pessoais e sociais.

\section{BREVE RELATO DOS FACTOS}

Quando, a 18 de março de 2020, foi decretado, pelo Presidente da República, o primeiro estado de emergência em Portugal, "face à situação excecional de saúde pública mundial e à proliferação de casos registados de contágio de Covid-19", já a Universidade do Porto tinha fechado, no dia 13 de março. Com efeito, na sequência da pausa breve do Carnaval, aproveitada por muitos portugueses para uma escapadela à Itália, onde o vírus já andava à solta, sem que se soubesse e, sobretudo no norte do país, em decorrência das muitas ligações locais à indústria têxtil e de calçado italiana, foi no norte, onde fica a Universidade do Porto, que os primeiros e mais sérios casos da pandemia começaram a se espalhar. Viemos para casa de um dia para o outro. O serviço de Tecnologias Educativas da Universidade ${ }^{2}$ montou, da noite para o dia, um sistema quase permanente de webinares e outras sessões informativas sobre as principais plataformas a usar, sobre como fazer filmes de aulas, sobre testes e exames a distância, enfim, sobre as principais formas de ultrapassar as dificuldades sentidas então pelos 2.567 docentes da instituição. Foi preciso fazer um levantamento rápido dos estudantes que precisavam de ajuda por não terem computadores (tendo a Flup, por exemplo, disponibilizado essa ferramenta a quem dela necessitou), ou, mais simplesmente, por terem ficado sem emprego e, consequentemente, sem salário, em situação de grande vulnerabilidade pessoal. A Associação de Estudantes e a Direção da Faculdade distribuíram cabazes de viveres a quem deles precisou e a Universidade acudiu às situações mais desesperadas, depois de feito um rápido levantamento. Imediatamente, lançámos mãos à obra, com muita inexperiência. Até ao dia 4 de maio de 2020, quando, muito lentamente e por períodos de 15 dias, o país começou a desconfinar, mantivemo-nos fechados em casa e com aulas exclusivamente a distância.

A partir do desconfinamento de maio de 2020, as creches e o ensino pré-escolar recomeçaram a abrir, mas alguns níveis de ensino já não abriram mais nesse ano letivo, por exemplo, todo o ensino básico, do primeiro ao terceiro ciclo. Voltou a abrir presencialmente o ensino secundário, nomeadamente o $12 .^{\circ}$ ano, por esses alunos terem exames nacionais em junho. Assim, para a esmagadora maioria dos alunos, as aulas presenciais só viriam a regressar, com regras muito estritas, no início do ano letivo 2020-2021, isto é, em setembro de 2020. Crianças, adolescentes e jovens adultos estiveram em casa de março a junho e, depois, em férias, com todos os custos que o estado de emergência teve para a respetiva formação, socialização e bem-estar psicológico.

Nos níveis de ensino que não o superior, a situação foi mais grave. Como lembra João Costa, secretário de Estado adjunto e da Educação, referindo-se à situação mundial,

De acordo com dados da UNESCO, mais de 1,5 mil milhões de crianças estiveram sem aulas, cerca de $90 \%$ dos estados tiveram as escolas com as portas

\footnotetext{
2 Disponível em: https://elearning.up.pt/. Acesso em: 12 abr. 2021.
} 
fechadas. O vocabulário da educação passou a integrar, quase de um dia para o outro, novas palavras: álcool-gel, bolha, aula síncrona, regime misto, isolamento (COSTA, 2021, p. 3).

As desigualdades inaceitáveis entre as pessoas não foram descobertas durante o confinamento, mas tornaram-se mais gritantes, como Carvalho e Soares (2021) afirmam.

Há crianças que fazem a sua única refeição decente do dia na cantina da escola que frequentam e foi, portanto, necessário, a partir de certa altura, que as escolas continuassem a fornecer almoços aos mais frágeis socialmente. Há famílias sem qualquer computador ou com apenas um para vários dos seus membros. Há casas sem rede de internet ou com rede de fraca potência. Por isso, uma parte das crianças, as mais desfavorecidas, ficou ainda mais para trás, sem acesso às aulas e longe do aconchego protetor da escola. Destaque-se, perante esta situação de urgência, o papel das autarquias locais, céleres no levantamento dos principais problemas, diagnosticados a partir de escolas e professores. Muitas dessas autarquias distribuíram tablets, computadores e acesso à internet aos munícipes mais necessitados.

Nessas circunstâncias, e atendendo aos relatos dos professores, que davam conta das crianças que não estavam a assistir às aulas on-line, o Ministério da Educação (ME) disponibilizou, em tempo record, já que o programa arrancou no dia 20 de abril de 2020, cerca de um mês depois do início do confinamento, um conjunto de aulas pela televisão, projeto herdeiro da velha Telescola (1966-2004) uma forma de ensino mediatizada com larga tradição nas zonas mais recônditas do país. O projeto \#EstudoEmCasa ${ }^{4}$ foi um dos mais louváveis que tivemos no tempo da pandemia. Com uma aplicação para telemóveis, descarregável gratuitamente $^{5}$, o programa passava também na Radiotelevisão Portuguesa (RTP), abrangendo crianças do ensino pré-escolar e de todo o ensino básico em 2020, mas também jovens do ensino secundário, já em 2021. Pela televisão, os alunos tiveram e têm aulas de todas as disciplinas do currículo, e também outras atividades, de cunho físico ou artístico, e a Hora do Conto, de que voltarei a falar. De repente, um grupo de professores generosos passou a dar aulas num estúdio de televisão transformado em sala de aula improvisada, mas as aulas foram gravadas ao vivo, sem edição nem hipótese de correção. A generosidade de quem assim se expôs aos olhares e à crítica de milhares de espectadores parece-me merecer apenas elogios. O \#EstudoEmCasa podia ser visto na modalidade de aulas ao vivo, isto é, quando estavam a acontecer pela primeira vez, num horário previamente divulgado e assinalado no sítio, mas elas também ficaram gravadas e estavam e estão ainda disponíveis, para os que não puderam assistir no momento que foram lecionadas pela primeira vez. Os familiares das crianças, que, em sua maioria, também estavam confinados, assistiram em massa a essas aulas, sendo a audiência dos programas muitíssimo mais elevada do que o número de alunos a quem se destinavam. Pais, avós, tios, muitos adultos voltaram

\footnotetext{
3 A partir do final dos anos 1960, a Ditadura portuguesa deu sinais de alguma abertura, da qual fez parte o ensino pela Telescola, em zonas mais isoladas do país. Essa forma de ensino teve um enorme sucesso na época e foi pioneira até do ponto de vista da inovação pedagógica.

4 Disponível em: https://www.rtp.pt/play/estudoemcasa/. Acesso em: 15 abr. 2021.

5 Em qualquer telemóvel, em qualquer parte do mundo.
} 
aos bancos da escola por meio do \#EstudoEmCasa ${ }^{6}$. Assim, os alunos do ensino pré-escolar até ao nono ano (no caso de 2020), além das aulas com os seus professores, pelas mais variadas plataformas, tiveram também acesso ao reforço das aulas pela RTP. E, deste modo, os que não tinham nem internet nem forma de a ela acederem, embora muito prejudicados, não foram esquecidos.

Ora, como se disse, além das aulas propriamente ditas das várias disciplinas ou matérias, os alunos tinham outras atividades no \#EstudoEmCasa, como propostas de exercício físico, atividades artísticas e cívicas e uma Hora do Conto, em que o primeiro livro lido foi A casa da mosca fosca, a que voltarei. Essa decisão teve lugar porque

Proporcionar às crianças que vivenciaram situações de emergência e pós-emergência, atividades estruturadas, significativas e criativas, seja em ambiente escolar ou em espaços informais de aprendizagem, ajuda-as a melhorar o seu bem-estar emocional e comportamental (BURDE et al., 2017 apud SILVA, 2021 , p. 57).

Um dos factos que pode explicar o sucesso de audiências do projeto, além da presença em casa e nas audiências de pais e outros familiares, foi a disponibilização do \#EstudoEmCasa a nivel internacional, pela RTP Internacional, nomeadamente para outros países da Comunidade de Países de Língua Portuguesa (CPLP), ou para crianças falantes de português como língua de herança, um pouco por todo o mundo. Com efeito, tendo em conta os inúmeros países por onde se espalha a diáspora portuguesa e em português, houve milhares de alunos que se beneficiaram do programa. O Camões - Instituto da Língua e da Cooperação, pertença do Ministério dos Negócios Estrangeiros, emprega, além de docentes em várias universidades por todo o mundo, professores de Português para os graus de ensino não superior, em todos aqueles países onde é ou foi muito forte a emigração portuguesa. Assim, vários países do mundo têm Ensino Português no Estrangeiro (EPE), havendo coordenações nos seguintes países: Espanha-Andorra, França, Suiça, Alemanha, Luxemburgo-Bélgica e Países Baixos, Inglaterra e Ilhas do Canal, Estados Unidos da América, Canadá, Venezuela, Austrália e, por fim, na África: África do Sul, Namíbia, Suazilândia, Zimbabué e Botsuana. O facto de haver, em certos países, coordenação do EPE significa que, nestas regiões do mundo, há um grupo consistente de professores de Português, pagos por Portugal, cujo desempenho profissional é preciso tutelar e coordenar. Quer isto dizer que, por onde, no mundo, houvesse uma criança falante de português, ela poderia (e pode, ainda) ter acesso ao \#EstudoEmCasa e às lições e atividades disponibilizadas. No que respeita aos países africanos de língua oficial portuguesa, o programa foi de grande proveito, dado o papel central da televisão, porque, com exceção de Cabo Verde, onde mais de metade da população tem acesso à internet, segundo Barbante e Ramos (2021, p. 8), tal como em parte significativa do "continente Africano, a rádio e a televisão são os principais meios de comunicação; já o acesso à internet ainda se restringe a uma minoria”.

Assim, foi com emoção que tive conhecimento de que umas crianças cabo-verdianas a morarem no Dubai, tinham, pela história A casa da mosca fosca ${ }^{7}$,

6 O próprio Presidente da República, Marcelo Rebelo de Sousa, professor catedrático aposentado de Direito, deu uma aula de Formação Cívica no \#EstudoEmCasa, sobre os tempos de pandemia, em 15 de junho de 2020, aula que teve uma audiência record, de crianças, adolescentes e adultos.

7 O "Estudo em Casa" realizou uma aula sobre a obra. Disponível em: https://www.rtp.pt/play/estudoemcasa/p7125/portugues-1-e-2-anos. Acesso em: 15 abr. 2021. 
de Eva Mejuto, a mesma fixação encantada que as minhas netas. Foi este o primeiro livro apresentado e lido na rubrica Hora do Conto, e imediatamente se tornou em motivo de conversa e comentário. A prova do sucesso do livro é que se esgotou nas vendas on-line e foi lido, depois, em vários locais e situações. Veja-se, por exemplo, este vídeo "1,2,3... Vamos ouvir outra vez - A Casa da Mosca Fosca", de responsabilidade da Câmara Municipal do Fundão, ou este outro, da Câmara Municipal de Sesimbra, "MOMENTOS COM HISTÓRIAS SESIMBRA \# 1 / Onde é a casa da Mosca Fosca?"9. De notar, ainda, que vários sítios publicaram, depois, atividades de todo género, nomeadamente plásticas, mas não apenas, para serem feitas a partir do livro ${ }^{10}$. Quero, portanto, sublinhar que algumas crianças que não têm livros em casa, ou cujos familiares não têm o hábito saudável de lhes lerem ou contarem histórias, acabaram por ter contacto, por meio do \#EstudoEmCasa, com um conjunto muito interessante de livros e histórias bem contadas, que, no seu quotidiano pré-pandemia, só poderiam encontrar na escola ${ }^{11}$. Esta reflexão, em tom otimista, permite-me passar para o tópico seguinte, em jeito de balanço.

\section{O gue se ganhou E O gue se Perdeu}

\section{O que se perdeu}

Comecemos pelo que se perdeu. Perdeu-se o essencial da relação pedagógica, que é fortemente mediada pelo corpo: o do professor e os dos seus alunos, sobretudo quando são mais pequenos e vão dar um beijinho ao professor, no final da aula, ou precisam da proximidade do docente quando têm dificuldades. Perdeu-se o crescer juntos, os jogos partilhados no recreio, o tempo da aula em comum, o brilhozinho nos olhos de quem aprende. E perderam-se, juntamente com esta falha de contacto, muitas aprendizagens. Não apenas afetivas, não apenas de socialização, aprendizagens mesmo (de conhecimentos e de competências). Mais: perdeu-se o trabalho que se vai fazendo para preencher as falhas dos mais frágeis, perdeu-se por se ter aprofundado ainda mais o fosso entre quem tem e quem não tem. Perderam, sobretudo (mas não apenas), aquelas crianças que vêm de ambientes desestruturados e para quem a escola é o oásis onde há adultos que podem servir de modelo, que dão colo e comida, sorriso e ajuda. Tal como escreve João Costa,

Educar é um ato relacional. O cérebro vai à escola, mas também vão o corpo e as emoções. Os melhores algoritmos do mundo não substituem o olhar atento do professor ao aluno que está perdido ou o que se intui a partir da postura. $O$ algoritmo não vê o brilho nos olhos do aluno que entende o que se the explica (COSTA, 2021, p. 5).

No que diz respeito às perdas de aprendizagens e competências, "As competências da leitura foram particularmente afetadas pela pandemia” (PORTUGAL,

8 Disponível em: https://www.youtube.com/watch?v=JaV_mPyBnyw. Acesso em: 15 abr. 2021.

9 Disponível em: https://www.youtube.com/watch?v=7YSgW1Kxn5Q. Acesso em: 15 abr. 2021.

10 Disponível em: https://www.pinterest.pt/teresatgd/a-casa-da-mosca-fosca/ ou https://www.pinterest.pt/marljamartine/a-casa-da-mosca-fosca/, por exemplo. Acesso em: 15 abr. 2021.

11 Como Silva (2021, p. 60) afirma: "Algumas pesquisas destacam também a importância da leitura e de numa situação ideal os alunos terem acesso a livros em casa. Esta medida é reconhecida por promover o sucesso educativo na vida adulta (Evidence for Learning, 2019; Sikora et al., 2019)". 
2021), conforme revelou o Estudo do Instituto de Avaliação Educativa (Iave), encarregado de um estudo diagnóstico amostral, com mais de 23 mil alunos dos terceiro, sexto e nono anos de escolaridade, sobre as maiores perdas das crianças e jovens portugueses. Segundo notícia publicada na RTP, "O estudo revelou que mais de metade dos alunos não conseguiu atingir os niveis esperados em conhecimentos elementares a Leitura, Matemática e Ciências” (LUSA, 2021).

Há já uma vastíssima literatura sobre o tema, com inúmeros relatórios que mostram a regressão de muitas aprendizagens e o tanto que os alunos, sobretudo os mais novos, perderam. Em face de um diagnóstico que coincide em diferentes países, trata-se, agora, de propor medidas que permitam recuperar ao máximo essas aprendizagens perdidas. É essa recuperação que se pretende agora incentivar, com o Plano de Recuperação de Aprendizagens, um investimento de mais de 900 milhões de euros, apresentado ao país no dia 1 de junho de 2021, significativamente, o Dia Mundial da Criança. Não é essa a primeira reflexão publicada pelo ME, uma vez que, já no início do ano letivo 2020-2021, o Ministério tinha divulgado amplamente um conjunto de Orientações para a Recuperação e Consolidação das Aprendizagens ao Longo do Ano Letivo de 2020/2021 (PORTUGAL, 2021).

Os maleficios foram menores no ensino superior no qual, porque os estudantes são já mais autónomos e mais habituados a trabalhar individualmente ou em grupo, fora dos momentos estritamente letivos, as perdas de aprendizagens e competências não foram tão penalizadoras.

Entretanto, no que diz respeito, sobretudo, aos mais pequenos e ao ensino básico, como João Costa assinala, foram vários os prejuízos do confinamento:

A dependência dos encarregados de educação tornou-se maior. A desigualdade de condições de estudo em casa - espaço individual, acesso a recursos informáticos - foi impeditiva de aprendizagens para muitos. A diminuição de sinalização de crianças às Comissões de Proteção de Crianças e Jovens foi preocupante. Percebeu-se também que a aprendizagem dos mais novos, com muito menor autonomia, se fez com muito mais dificuldade (COSTA, 2021, p. 4).

Com efeito, os pais, muitos deles em teletrabalho, outros em empregos essenciais, passaram a ter de gerir, também, a aprendizagem dos filhos: as ligações às aulas, os trabalhos que precisavam de apoio, as tarefas que era necessário explicar mais claramente.

\section{O que se ganhou}

No meu caso concreto, e creio que no de muitos colegas professores de diferentes graus de ensino, ganhei a reflexão imprevista sobre o ensino ministrado e também experiências novas, e muito mais do que tinha feito até ao confinamento, por exemplo, ter experienciado as vantagens de uma espécie de "aula invertida", em que muita da informação se adquire fora dela e o espaço de aula é ocupado com a discussão coletiva e a problematização crítica da informação já obtida, sendo parte da preparação feita antes da sessão, mas conduzida pelo docente. O conceito de flipping classroom (KIM; KHERA; GETMAN, 2014; BERRETT, 2012), com o essencial da aquisição de informação a ocorrer antes da aula, que assim se preenche com projetos de grupo e discussões coletivas, embora não 
tenha sido seguido em toda a sua extensão, inspirou, no contexto das aulas on-line durante os dois confinamentos, o trabalho realizado, com evidentes ganhos em responsabilização e autonomia dos estudantes.

Com efeito, antes das aulas síncronas no Zoom, colocava, no Google Classroom, plataforma que me pareceu mais versátil e intuitiva do que o Moodle, usado esmagadoramente na Universidade do Porto, quer textos teóricos que os estudantes deveriam ler, sempre acompanhados de tópicos de reflexão, ou questões a que deveriam responder, vídeos em que eu expunha matéria com cuja exposição não queria estar a gastar o tempo da aula síncrona, ou tarefas que os estudantes deveriam realizar em casa. Essa disponibilização de informação e as orientações fornecidas para que os estudantes fossem trabalhando, individualmente ou em grupos, em casa, permitiam que as aulas síncronas fossem sobretudo de discussão, muitas vezes em grupos, nas salas simultâneas do Zoom e que depois partilhássemos as conclusões dos diferentes grupos, nos momentos de regresso ao encontro na chamada "sala principal".

O facto de os estudantes já estarem habituados, nas unidades curriculares por mim lecionadas, a realizarem em casa um trabalho prévio a cada aula (ou de leitura orientada por guiões, de textos teóricos depois comentados em aula, ou de construção de propostas práticas, para tarefas de planificação a apresentar e discutir em aulas práticas), facilitou, a meu ver, a transição para um tipo de ensino em que se acentuou o trabalho assíncrono. Na verdade, sem experiência com o EaD, nos primeiros tempos, sobrecarregámos os estudantes com tarefas extra-aula, propostas de trabalho assíncrono que tiveram o mérito de os manter ocupados nos momentos de maior tensão e medo, mas, por termos proposto um volume de trabalho excessivo, quer para os discentes quer, depois, para os docentes, que tinham de comentar os diversos trabalhos entregues, teve de se reequilibrar o montante de tarefas solicitadas aos estudantes. Por via dessas readaptações, no entanto, foi possivel pensar sobre metodologias de ensino e afinar aquelas que melhores resultados foram dando. Na verdade, tal como Silva (2021) advoga, acreditamos que muito do que experimentámos pode vir a ser útil para combinarmos o EaD com o indispensável e tão desejado ensino presencial:

A recente demanda pela aprendizagem a distância aconteceu muito rapidamente, impactando o planeamento escolar e as rotinas do educador. O setor de ensino especializado em educação a distância, que nem sempre foi ouvido, poderia prestar um serviço importante, contribuindo com orientações importantes para uma transição suave, evitando sentimentos de frustração dos e-tutores (Pedro, 2020). A adoção de uma abordagem de aprendizagem combinada tem o apelo de mesclar diferentes elementos de aprendizagem, usando o poder das TIC enquanto é preservado o toque humano, o que pode ser uma mais-valia acrescida em idades precoces (Silva \& Coutinho, 2017). [...] A contingência atual apela a um renovado impeto para reexaminar os beneficios de fornecer programas mistos que combinam a aprendizagem presencial e a aprendizagem online e há evidências que sugerem que "para muitos estudantes a aprendizagem combinada pode ser tão eficaz quanto a aprendizagem em sala de aula" (BROWN et al., 2020, p. 1 apud SILVA, 2021, p. 57).

O relato de algumas experiências no âmbito de certas competências concretas, no que tange ao ensino de Português, por exemplo, o desenvolvimento da 
competência de escrita ${ }^{12}$, testemunha os ganhos conseguidos que não deveremos ignorar quando o ensino presencial voltar em pleno. Já as experiências de estágio profissional on-line, que, no primeiro confinamento de 2020, foram totalmente improvisadas e com prejuízo visivel para os jovens professores, puderam ser, no segundo confinamento, de 2021, organizadas de modo muito mais racional e proveitoso, quer para os estagiários quer para os respetivos alunos a quem as suas aulas se destinavam. Dentro dos ganhos, contabilizo ainda as inúmeras sessões de formação organizadas por todo lado, nomeadamente as que o foram na Flup, e que tiveram por objetivo dar a conhecer os beneficios de alguns programas e aplicações on-line, porventura mais atrativos para a aquisição de certos conteúdos programáticos e para o treino de certas competências.

Uma outra vertente em que algo se ganhou foi na relação pais/filhos, ou pais/professores. Os primeiros partilharam, inesperadamente, um tempo de incerteza e improviso, em que o convivio em torno das questões escolares se tornou quotidiano e obrigatório. Os pais passaram a compreender melhor as aprendizagens dos filhos, o seu dia a dia escolar, as tarefas em causa, mas, também, entraram mais em contacto com os professores dos filhos, para pedirem esclarecimentos, pedirem ajuda para dificuldades, esclarecerem comportamentos etc. Como afirma Alaiz (2020, p. 136-137):

Para quem se habituou a considerar que o sistema educativo mundial se encontrava demasiado ligado a um modelo escolar tradicional, inadaptado aos novos tempos, convenhamos que surpreende a rapidez da metamorfose que foi capaz de realizar. Diríamos que a escola, na senda da profecia de M. McLuhan, ao mesmo tempo que se alargou, que se estendeu geograficamente, também encurtou distâncias: entre professores e alunos (aumentando as interações diferenciadas); e, sobretudo, entre filhos e pais.

O envolvimento dos pais na educação dos filhos, se se traduziu numa sobrecarga para eles, já que a maioria estava em casa, mas em teletrabalho, também teve a vantagem de aproximar pais e filhos em torno da escola e das aprendizagens. E tudo isso aconteceu em tempo record, numa instituição que costumávamos achar anquilosada e incapaz de adaptação à mudança. Essa resistência à mudança, aliás, foi detetada no trabalho de Duarte et al. (2021), a partir de um inquérito por questionário com respostas de 287 professores / as do primeiro ciclo do ensino básico, durante o ano letivo 2019/2020, apesar da constatação do esforço levado a cabo por esses professores para conseguirem ensinar o mais eficazmente possivel. Para tal, muitos docentes utilizaram, pela primeira vez, aplicações para tornarem o ensino mais atrativo e captarem a atenção dos alunos. Experimentaram ensinar por meio de jogos e outros materiais não tradicionais, pensaram na intencionalidade e na eficácia das estratégias que iam aplicando.

Com efeito, desperdiçar os muitos ganhos que se obtiveram com o EaD não parece uma atitude sensata. Nunca mais será possivel dispensar as plataformas que podem auxiliar professores e estudantes, nem todo um conjunto de aplicações e programas que facilitam aprendizagens autónomas e adaptadas aos ritmos dos aprendentes. E será insensato desperdiçar a aproximação entre os

12 Ver a intervenção da colega Sónia Rodrigues (2020) sobre "A escrita no ensino remoto de emergência em Portugal: contributo para uma reflexão". 
diversos atores que a pandemia possibilitou: pais, filhos, professores, escolas, comunidade.

\section{O gUE FAZER?}

Se este foi um tempo de crise profunda, há que aproveitar o "desequilíbrio em que sabemos que estamos a ser compelidos a trabalhar, ou seja, [d]as sementes de mudança e melhoria do modelo escolar" (AZEVEDO, 2020, p. 85). Essas mudanças e melhorias dependem, segundo Joaquim Azevedo ${ }^{13}$, de "um processo de reflexão-ação que é preciso organizar (urgentemente) em cada escola e $\mathrm{AE}^{\text {"14, }}$ para que se possa transformar os constrangimentos em oportunidades.

Como se foi dizendo, as consequências nefastas da pandemia na educação não se fizeram sentir do mesmo modo no ensino superior, ou mesmo no secundário e nos grupos de crianças mais novas. Repetimos que, para essas, os danos foram mais graves, deixando-as em situação de vulnerabilidade social.

Neste momento, em Portugal, o ME apresentou já documentação e medidas que permitem minimizar os danos e recuperar as aprendizagens perdidas. Como João Costa (2021, p. 4) afirma, é urgente proteger os mais frágeis:

Identificaram-se grupos específicos a que não se devem aplicar o ensino misto $e$ não presencial: alunos até ao segundo ciclo, alunos que beneficiam de terapia em contexto escolar, alunos em risco sinalizados pelas $C P C J^{15}$, alunos com quem a escola não consegue manter contacto. Proteger estes grupos é travar o acelerador de desigualdades que esta pandemia trouxe.

Por outro lado, foram elencadas quais as aprendizagens essenciais que não se realizaram e que são prioritárias. Costa (2021, p. 4), que é linguista de formação, diz, na mesma página: "Por exemplo, é possivel ler uma obra sem ter lido uma outra, mas é dificil aprender a ler com fluência se não tiver descoberto a relação entre grafemas e fonemas". Escolas, professores e ME tratam de perceber agora, para tentarem remediar, quais aprendizagens essenciais estão em falta, para que possam ser recuperadas.

Porém, sabendo que não foram só as aprendizagens a sofrer com a pandemia, mas que a saúde mental de muitas crianças, adolescentes e jovens foi fortemente ameaçada com o isolamento, com a solidão, com vivências de conflitualidade doméstica que a escola, normalmente, atenua, o ME lançou uma candidatura a planos de intervenção nesta área. Consoante informação do próprio secretário de Estado, "As escolas responderam com mais de 600 planos de grande interesse, o que permite a afetação de 900 técnicos que incluem psicólogos sociais e educacionais, mediadores socioculturais, artistas residentes, assistentes sociais" (COSTA, 2021, p. 4), tendo por intenção última a redução das desigualdades que a pandemia fez crescer. Como o autor defende,

[...] a escola garante mobilidade social porque é transmissora de conhecimento [...] - mas também porque garante aos que menos têm a atenção personalizada, a refeição que não existe em casa, a proteção quando está em risco,o afeto que falha noutros espaços (COSTA, 2021, p. 5-6).

\footnotetext{
13 Que também já ocupou o cargo de secretário de Estado da Educação.

14 Agrupamentos de escolas de diferentes níveis que funcionam de forma organizada.

15 Centros de proteção de crianças e jovens do Ministério da Justiça, encarregados de seguir crianças em risco.
} 
Dentro das medidas para o futuro, saliente-se o reforço da chamada "transição digital": foram distribuídos mais de 450 mil computadores para os alunos que ainda não possuíam este equipamento, houve formação contínua para todos os professores dos ensinos básico e secundário na área do digital, mas sublinhe-se, acima de tudo, a ideia de que todos dependemos de todos, de que a colaboração entre escolas/pais/comunidade, essencial no tempo estranho que vivemos, é crucial para avançarmos, sem que ninguém fique para trás.

\section{EDUCATION IN TIMES OF PANDEMIC: "BRAKING THE INEgUALITIES ACCELERATOR": observations From PORTUgal}

Abstract: Taking as a starting point the observations on the author's experience as a professor at the Faculty of Arts and Humanities of Porto University, during the two confinements caused by Covid-19, the text critically reports the main steps of what was done in Portugal, with regard to emergency remote teaching, and equates the losses in knowledge and skills, but also the constraints that became opportunities in this area. In the end, paths for the future are pointed out.

Keywords: Covid-19. Portugal. Remote learning. Inequalities. Opportunities.

\section{REFERÊNCIAS}

ALAIZ, V. Impactos: metamorfoses, desigualdades e... expectativas. In: ALVES. J. M.; CABRAL, I. (org.). Ensinar e aprender em tempos de COVID-19: entre o caos e a redenção. Porto: Faculdade de Educação e Psicologia da Universidade Católica Portuguesa, 2020. p. 135-139.

AZEVEDO, J. COVID e educação: da emergência às oportunidades. In: ALVES. J. M.; CABRAL, I. (org.). Ensinar e aprender em tempos de COVID-19: entre o caos e a redenção. Porto: Faculdade de Educação e Psicologia da Universidade Católica Portuguesa, 2020. p. 83-86.

BARBANTE, C. J. S.; RAMOS, M. A. S. A Educação nos PALOP em tempos de pandemia da COVID-19. Sensos-E, Porto, v. 8, n. 1, p. 5-11, 2021. DOI 10.34630/ sensose.v8i1.3758

BERRETT, D. How 'flipping' the classroom can improve the traditional lecture. The Chronicle Of Higher Education, 19 fev. 2012. Disponivel em: https: / people. ok.ubc.ca/cstother/How_Flipping_the_Classroom_Can_Improve_the_Traditional_Lecture.pdf. Acesso em: 4 maio 2021.

CARVALHO, M.; SOARES, D. Acesso, equidade e aprendizagem: desafios em tempos de Covid. In: ALVES, J. M.; CABRAL, I. (org.). Ensinar e aprender em tempos de COVID19: entre o caos e a redenção. Porto: Faculdade de Educação e Psicologia da Universidade Católica Portuguesa, 2020. p. 119-122.

COSTA, J. As escolas fecharam, a educação não ficou suspensa. Saber \& Educar, Porto, n. 29, 2021. DOI 10.17346/se.vol29.401. Disponivel em: http://revista. esepf.pt/index.php/sabereducar/article/view/401. Acesso em: 15 abr. 2021. 
DUARTE, P. et al. Na encruzilhada de opções educativas: um estudo exploratório sobre o ensino a distância no $1 .^{\circ}$ Ciclo do Ensino Básico. Sensos-E, Porto, v. 8, n. 1, p. 64-76, 2021. DOI 10.34630/sensose.v8i1.3788

FRAGA, N. et al. Educação em tempos de COVID-19: o acesso condicionado à aprendizagem. Um estudo exploratório numa escola em Portugal. Sensos-E, Porto, v. 8, n. 1, p. 77-87, 2021. DOI 10.34630/sensose.v8i1.3786

KIM, S. M.; KHERA, O.; GETMAN, J. The experience of three flipped classrooms in an urban university: an exploration of design principles. The Internet and Higher Education, v. 22, p. 37-50, jul. 2014. DOI 10.1016/j.iheduc.2014.04.003

LUSA. Governo revela plano de recuperação das aprendizagens dos alunos. RTP Noticias, $1^{\circ}$ jun. 2021. Disponivel em: https://www.rtp.pt/noticias/pais/governo-revela-plano-de-recuperacao-das-aprendizagens-dos-alunos_n 1324440 . Acesso em: 2 jun. 2021.

MEJUTO, E. A casa da mosca fosca. Tradução Dora Isabel Batalim. Ilustração Sergio Mora. Matosinhos: Kalandraka, 2004.

PORTUGAL. Ministério da Educação. Orientações para a Recuperação e Consolidação das Aprendizagens ao Longo do Ano Letivo de 2020/2021. Lisboa: Ministério da Educação, 2021. Disponivel em: https://www.dge.mec.pt/sites/ default/files/orientacoes_2020.pdf. Acesso em: 15 abr. 2021.

RODRIGUES, S. A escrita no ensino remoto de emergência em Portugal: contributo para uma reflexão. In: Ciclo de Palestras sobre Produção Textual, 4., 2020, [s. 1.]. A escrita [...]. Maceió: Universidade Federal de Alagoas, 2020. Disponível em: https://doity.com.br/iv-ciclo-de-palestras-sobre-producao-live1. Acesso em: 15 abr. 2021.

SILVA, V. COVID-19 e ensino remoto: uma breve revisão da literatura. Sensos-E, Porto, v. 8, n. 1, p. 55-63, 2021. DOI 10.34630/sensose.v8i1.3777 